\section{Evidence-based medicine and guidelines}

I feel it necessary to join the discussion about evidence-based medicine (EBM) and guidelines. I am dismayed about the constant negative attitude towards new contraceptives that are badly needed

I do not believe (serious safety issues aside) that contraceptives should be viewed in entirely the same light as drugs used for a medicinal purpose; in the latter some minor adverse side effects are tolerated provided the overall risk/benefit balance is acceptable for the condition being treated. With contraception, both efficacy and minor side effects are equally important Indeed, for some women, the balance is reversed with a poorer efficacy being tolerated in favour of lesser or more acceptable side effects.

The proponents of EBM have lost sight of the fact that most of what we do in family planning is not based on what would now be considered good evidence, and that it is reasonable to make certain assumptions. Last year the Clinical Effectivenes Unit's Product Review of Cerazette ${ }^{\circledR 1}$ stated: “... an evidence-based recommendation cannot be made that the desogestrel pill is different from other POPs in terms of efficacy ....", while the Drug and Therapeutics Bulletin ${ }^{2}$ went further: "...there is insufficient evidence on whether it is a more effective contraceptive than other POPs..." and "... we believe the company's claim that Cerazette has the 'efficacy of a combined pill' is unsubstantiated and should be withdrawn". Less than a year later, the product licence for Cerazette has been officially altered to allow a 12 -hour pilltaking leeway ${ }^{3}$ - the same as for the combined pill. To most of us, this had been obvious from the start: while acknowledging a lack of good evidence, why could those writing the product reviews not have been less scathing, more willing to use a little common sense? Similar attacks have been made on both Evra ${ }^{\circledR}$ and Yasmin ${ }^{\circledR}$, which should be welcomed as providing alternatives for women who may not have found a method that suits them.

Choice is extremely important: a woman may wish to use a product simply because her friend is happy with it. This may not be evidencebased, but if it will improve her compliance then it may be less expensive than paying for her termination of pregnancy. Most modern contraceptives are very good: should we only have the one and tell women there is so little difference between them that it will do? Perhaps the Drug and Therapeutics Bulletin should learn the Drug and Therapeutics Bulletin should learn
from how people use its sister publication Which? When I want to buy a washing machine, I migh not chose their evidence-based top product if it doesn't match my kitchen, however well it washes my clothes.

Barbara Hollingworth, DRCOG, MFFP Consultant and Lead Clinician, Redbridge and Havering PCTs, Surrey, UK. E-mail: bah@lupins.plus.co.com

References
$1 \quad$ New Prod

New Product Review: Desogestrel-only pill (Cerazette) $J$ Fam Plann Reprod Health Care 2003; 29(3): 162-164. Is Cerazette

Cerazette. (UK SmPC 03 Cera v1.3). Electronic Medicines
Compendium, 8 July 2004. http://emc.medicines org us compendium, 8 July 2004. http://emc.medicines.org.
$\mathrm{mc} /$ assets/c/html/displaydoc.asp?documentid=10098.

\section{Role of nurses}

\section{Madam}

The Nursing Focus article ${ }^{1}$ by Pam Campbell in the July 2004 edition of the Journal raised the important issue of the enhanced nurse role, which is not being fully utilised in many areas. Unfortunately, the barriers to implementing this role for nurses are not limited to lack of 'commitment and support from doctors and managers'. With the best will in the world, certain recurrent obstacles have been present in my experience in three different family planning services.

First, it is extremely difficult to find extra nurses to cover sessions while others are training Even when a nurse takes annual leave there is often a gap in the service, so sending nurses on a 6-month rotation in another department would be highly detrimental to service provision. Even if a nurse were sent from the other department as a 'swap', extra staff would be needed to train and supervise the visiting nurse's practice. An alternative would be to pay the nurse to attend sessions elsewhere at a time other than their normal work session; however, as pointed out in the article, many family planning nurses have full-time jobs in other departments and this could prove difficult.

Second, family planning services tend to be run on a 'shoestring' budget with little leeway for the expense involved in achieving adequate nurse training and the extra expense for enhanced training and the extra expense for
remuneration following said training.

Third, there are some nurses who refuse to
Theration following said training. take on an enhanced role even when training is offered, hiding behind the Nursing an Midwifery Council's (NMC) requirement to recognise their own 'scope of practice' and to work only within their area of competence, which they decline to expand. This can lead to resentment in the workplace as they receive the same pay as nurses who have developed themselves and appear to be working harder.

Fourth, a nurse who has been developed in the workplace by a particular service may find it difficult to transfer these skills if she gets a family planning job in another service, and the new employer is obliged to provide repeat 'in-house' training and assessment because the nurse does not have a nationally recognised qualification. This can be difficult and confusing for nurses who work simultaneously for two or three different family planning services in their area, because Patient Group Directions (PGDs) are independently produced by each service with varying levels of produced by each service with varying levels of
freedoms for nurse supply and administration of freedoms for nurse supply and administration of
drugs. It is not common practice for nurses to issue drugs. It is not common practice for nurses to issue prescriptions to clients in family planning clinics, as supplies are no

These problems cannot be solved by doctors nd managers alone; there needs to be a national plan for the introduction of modernised nurse training standards and practice, ideally driven by liaison between the NMC, the Faculty of Family Planning and Reproductive Health Care and the British Association for Sexual Health and HIV, to ensure that basic training for family planning nurses covers all aspects of care included in Level 1 of the national sexual health strategy. ${ }^{2}$ The syllabus should include the understanding and use of PGDs and the practical sessions should result in the nurse being able to work to PGDs. There should also be time devoted to attendance at genitourinary, pregnancy termination and colposcopy clinics as standard.

There ought to be nationally agreed PGDs for all contraceptive methods and drugs used for treatment of sexually transmitted infections, which would save the immense amount of time and effor which is expended in producing individual PGD for each Trust or service in the country. This would mean that a nurse who has in-house training to use PGDs in one service could then carry this competence with her to any other employer.

Finally, the development of letters of competence or similar certification for nurses in skills such as swab taking, smear taking, implan insertion, implant removal, intrauterine device (IUD) insertion and IUD removal would allow nurses to gradually develop a skill base that is transferable and nationally recognised.

Linking these evidence-based skills to remuneration can now be enabled by the Agenda for Change. ${ }^{3}$ Graded remuneration may encourage nurses to take up family planning as a career rather than a job on the side, leading to greater job satisfaction. Nurses spending more time practising their skills will feel more confident and competent, which is beneficial to both them and their clients. Managers can help in this respect by redesigning their services to provide long daytime sessions (e. . 11am-6pm or $12-7 \mathrm{pm}$ ) rather than the traditional 2-hou sessions, allowing for more effective use of clinical time, greater client choice of attendance time, and less time wasted on setting up and clearing away clinic trolleys and equipment. Staff will also feel more ownership of the service and it is easier to offer full-time jobs with more prospect of career progression.

Lydia Kingsley, MB ChB, MFFP

Director of Family Planning and Reproductive Health, St Helens PCT, Cowlet Hill Lane, St Helens WA10 2AP, UK

References

Campbell P. The role of nurses in sexual and reproductive health.

t of Healh. Nutional Strategy for Sexual Healt and HIV. London, UK: Department of Health, 2001

Department of Health. Agenda for Change: Modernising the of Health, 1999 .

\section{Reply}

I agree that if services are to invest in nurses this may involve an initial need to increase staffing levels in order to cope with rotation into othe areas. Although family planning services do attract a very small budget, initiatives that blend family planning with wider sexual health services should be able to attract further funding because of the strong recommendations for this from the sexual health strategy. Now is the time to move on this!

It is a fact that some nurses do not wish to take on extra responsibilities. However, the introduction of the Knowledge and Skills Framework in Agenda for Change 1 will differentiate between these staff and others who are committed to increasing their clinical skills. Remuneration will therefore be more fairly linked to work undertaken.

The comments regarding nationally approved standards for training echo the thoughts in my article. The development of a portfolio of competence measured against these standards would be an excellent move forward. Perhaps the sexual health leads within strategic health authorities could be asked to take these ideas forward for national debate and co-ordination with the Nursing and Midwifery Council.

Pam Campbell, MSc, RGN

Principal Lecturer, Primary Care Nursing, Staffordshire University, Blackheath Lane, Stafford, Staffordshire ST18 OAD, UK

Reference

Department of Health. Agenda for Change: Modernising the NHS Pay System. HSC 1999/227.

\section{Missing IUD fragment}

\section{Madam}

The case report of Nadgir et al. ${ }^{1}$ recommends that if a small fragment of an intrauterine contraceptive device (IUD) is found to be missing and cannot be retrieved by hysteroscopy or laparoscopy then laparotomy is necessary.

This advice is neither pragmatic nor evidence based. The chances of finding a small portion of an IUD at laparotomy are remote and would require an extensive midline incision. The subsequent morbidity (adhesion formation subacute obstruction, etc) considerably outweighs a theoretical risk of intestinal perforation, which even in the unlikely event of it occurring, is not likely to cause a major degree of peritonitis.

Peter Bowen-Simpkins, FRCOG

Consultant Gynaecologist, Singleton Hospital, Sketty Lane, Sketty, Swansea SA2 8QA, UK

Reference

Nadgir A, Beere D, Barker K. Intrauterine fragmentation of Gyne T380: an uncommon complication. J Fam Plan
Reprod Health Care 2004; 30: 175-176. 